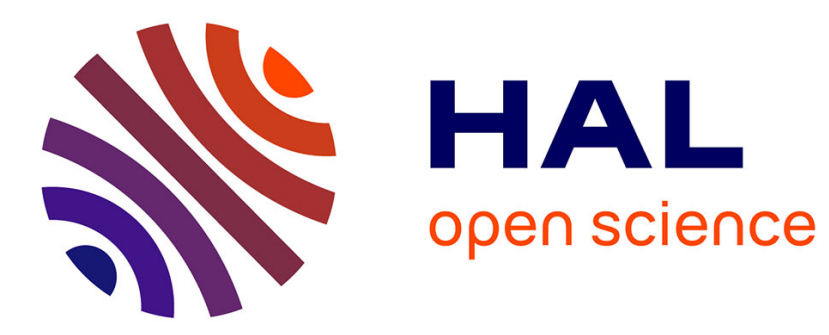

\title{
The puzzle of older workers' employment: Distance to retirement and health effects
}

Bérangère Legendre, Mareva Sabatier

\section{To cite this version:}

Bérangère Legendre, Mareva Sabatier. The puzzle of older workers' employment: Distance to retirement and health effects. International Journal of Manpower, 2017, 38 (1), pp.45-61. 10.1108/IJM02-2016-0042 . hal-01522749

\section{HAL Id: hal-01522749 \\ https://hal.science/hal-01522749}

Submitted on 15 May 2017

HAL is a multi-disciplinary open access archive for the deposit and dissemination of scientific research documents, whether they are published or not. The documents may come from teaching and research institutions in France or abroad, or from public or private research centers.
L'archive ouverte pluridisciplinaire HAL, est destinée au dépôt et à la diffusion de documents scientifiques de niveau recherche, publiés ou non, émanant des établissements d'enseignement et de recherche français ou étrangers, des laboratoires publics ou privés. 


\title{
The puzzle of older workers' employment: Distance to retirement and health effects
}

By Bérangère Legendre ${ }^{1}$ and Maréva Sabatier ${ }^{2}$

\begin{abstract}
This article investigates the extent to which the distance to retirement affects low employment rates among European older workers, taking into account a key but often neglected determinant: health status. To begin, the study amends McCall's job search model, in which the job search behavior is treated as age dependent. Agents are heterogeneous according to two attributes: distance to retirement and health. This model leads to clear predictions, such that the closer the retirement, the greater the reservation wage and the lower people's search effort. Older workers also exhibit lower exit rates from unemployment, an effect that gets enhanced by health problems. This empirical work, based on a French survey, confirms the existence of a distance effect but also puts the greater impact of health status into perspective. The distance effect explains only part of the puzzle of older workers' employment.
\end{abstract}

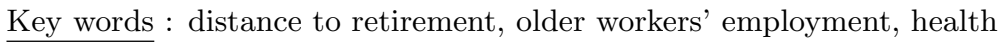
JEL Codes: I10, J26, J64

\footnotetext{
${ }^{1}$ IREGE - Université de Savoie - 4, chemin de Bellevue - BP 80439, 74944 Annecy-Le-Vieux Cedex

${ }^{2}$ IREGE - Université de Savoie - 4, chemin de Bellevue - BP 80439, 74944 Annecy-Le-Vieux Cedex ; LIEPP - Science Po. Paris
} 


\section{Introduction}

Since the 1970s, European employment rates have remained far below the U.S. employment rate. This difference seems especially pronounced among older workers (over 55 years). In 2014, the average employment rate of older workers in the European Union (EU27) was 51.8\%, versus $61.4 \%$ in the United States. Europe in turn has been deprived of a segment of its workforce and a potential source of growth. Such trends also call into question the sustainability of European pension systems, which mainly are based on a pay-as-you-go (PAYG) approach that already has been challenged by the aging of the population. France seems particularly worrisome. In 1975, the employment rate of elderly aged from 55 to 59 reached 60,1\%. In 1995, it was only $43.9 \%$. Only in the 2000's, this employment rate has increased again. In 2014, the employment rate of older workers (48.6\%) remains 3.2 points lower than the EU average and 12.8 points lower than the U.S.

To explain these differences between Europe and the United States, several authors (Nickell[40], 1997 ; Abowd et al.[1], 1999 ; Blanchard and Wolfers[11], 2000 ; Saint-Paul, 2009[44]) emphasize the role of institutions (e.g, minimum wage, employment protection, taxation, unemployment benefits) which tend to be stronger in Europe and particularly in France. These institutions create rigidities in the labor market that might help to explain low employment rates. For older workers, institutional retirement conditions, such as the presence of a legal retirement age, seem influential : if the legal retirement age is low, older workers feel encouraged to leave the labor market earlier. This negative correlation between retirement age and older workers' employment rate can be clearly observed in OECD countries.

This stylized fact also implies a distance effect, such that the legal retirement age acts as a deadline for older workers. Life-cycle supply models (Seater, 1977[45]; Bettendorf and Broer, 2003[10]) demonstrate how this deadline affects both labor demand and the search behavior of older workers. Because their employment horizon is shorter, older workers expect lower returns to their job search, which lowers their incentives to the point that older workers rationally display lower search effort (Ljungqvist and Sargent, 2008[35]). This negative effect gets reinforced by the presence of generous unemployment benefits, pensions, or pre-retirement plans (Hairault, Langot and Sopraseuth (2010[27]). In those cases, the affordability of retirement is not a question : in France and in other european countries, the public pension system provides sufficiently high benefits to cover basic needs. Symmetrically, a shorter employment horizon also decreases the returns to hiring an older worker, such that hiring and training costs might appear too high, compared with the limited flow of expected returns (Hutchens, 1986[30] and 1988[31]). Moreover, with a shorter horizon, firms might have difficulties monitoring older workers or offering them incentives based on delayed compensation schemes (Lazear, 1979, 1981; Hirsch et al., 2000[29]). Finally, according to Cheron, Hairault and Langot (2007[19], 2011[20]), 
the distance effect creates an incites for firms to fire older workers in response to economic difficulties appear. Older workers have less time to identify new opportunities so the separation decisions for older workers depend mainly on instantaneous profit. The closer the date of retirement, the lower the expected value of employing a senior and the greater the risk of being laid-off becomes. This risk is even reinforced if older workers suffer from a technological bias that assigns greater importance to skill obsolescence (Aubert, Caroli and Roger, 2006[5]).

This theoretical framework helps clarify why older workers' employment rate is lower in Europe and France, as well as point to directions for solving the problem. Postponing the legal retirement age would almost automatically increase the older workers' employment rate, as well as restore the funding capacity of the PAYG system by increasing the number of active people and limiting the number of retirees. Because of this double dividend, several countries have decided to delay the legal retirement age. In France, it has increased gradually from 60 years (in 1983) to 62 years (following the 2010 reform), leading older workers retire to later (Bozio, 2008 [15]). But these workers also experience significant difficulties in finding jobs. In France for example, the proportion of older people (over 55 years) in employment rose from $7.5 \%$ in 1995 to $12.9 \%$ in 2011 , even as their share in unemployment doubled, from $4.3 \%$ in 1995 to $8,9 \%$ in 2011 . That is, postponing the retirement age led the activity rate of older workers to increase, but so did their unemployment rate. The effect on the employment rate also seems less important than predicted by life-cycle models.

Although attractive, the distance effect framework cannot piece together the entire puzzle of older workers' employment in Europe or in France, likely because life-cycle supply models suffer from two limitations that limit the scope of their predictions for economic policies in Europe. First, life-cycle job search models rely on rather unrealistic hypotheses for European labor markets, such assuming that older workers have lower reservation wages than young unemployed people (Hairault, Langot, Sopraseuth, 2010). However, in most European countries, seniority pay systems ensure that older workers receive higher wages than younger workers in equivalent positions. In addition, unemployment benefits generally are calculated according to the most recent salary received, so European older workers are likely to have higher reservation wages. Second, in life-cycle models agents are heterogenous in age but match in their other characteristics. However, workers often differ in terms of their health status, particularly at the end of their careers. A growing literature stream (Currie and Madrian (1999[21]; Gruber and Wise (1999[24]); Cai and Kalb, 2006[18] and 2007; Barnay, 2005[7] and 2008[8]; Blanchet and Debrand, 2005[12]; Jones, Rice and Roberts, 2010[32] ; Garcia-Gomez, 2011[23]) shows that health is a key determinant of early retirement in that health problems can decrease labor productivity and weaken the position of older workers. These problems also can make workers 
more sensitive to poor working conditions and enhance labor opportunity costs, especially if financial compensation is available, which often depends on the severity of the disability. Poor health can expose workers to discriminatory practices by employers too (Madden, 2004[36]). Overall then elderly workers with poor health may have a strong incentive to retire earlier.

Our main goal with this research therefore is to specify the contribution of the distance effect to the low employment rate of European older workers, taking into account both health status and the specificities of European labor markets. To fulfill that goal, we first amend McCall's (1970) job search model, in which job search behavior is solely dependent on age. However, we do not assume several homogenous cohorts of workers, as in Ljungqvist and Sargent (2008[35]) or Hairault, Langot and Sopraseuth (2010[27]). Instead, we anticipate that agents are clearly heterogenous according to two attributes : distance to retirement and health. As our main theoretical contribution, we predict that search behavior (both the job offer arrival rate and search costs) depends on the distance to retirement and health status. We also endogenize the separation rate, which depends negatively on retirement distance. Our model in turn offers clear predictions, in that when the distance to retirement is lower, the reservation wage increases, whereas search effort declines. Finally, older workers exhibit lower exit rates from unemployment and thus lower employment rates, effects enhanced by health problems.

In order to test empirically whether the distance to retirement and the health status impact the employment status, we use a French data set on health and career paths, the "Santé et Itinéraires professionnels" survey (SIP), conducted in 2006 by the France's health and labour ministries. This original survey provides retrospective information on both employment and health status. We focus on men who entered the labor market after 1960, and exploit the panel dimension of the survey. The data pertain to more than 3700 individuals, with information on them between 1 and 46 years. For each worker, we can calculate the distance to retirement annually on the basis on the legal rules in place. Using dynamic probit models and controlling for initial conditions (Heckman, 1981), we estimate the distance effect on the probability of being employed, and we test the influence of health on this distance effect.

The next section presents the job search model, with which we take into account the impact of the distance to retirement and health status. Section 3 presents the data and the empirical approach. In Section 4 we present the results, and Section 5 concludes. 


\section{Theoretical Model}

In McCall's (1970) job search model, the distance to retirement and health status both have an on impact the agent's search effort and probability of getting a job.

\subsection{Hypotheses}

We consider a partial equilibrium job search model with endogenous individual search intensity (Burdett and Mortensen, 1980[17] ; Mortensen, 1986[39]). This framework allows us to analyse search behavior and thus employment rates of heterogenous individuals in terms of distance (and health) at time $t$. Individual job search is thus assumed to be stationary. This hypothesis does not allow us to study how search behavior varies when an individual gets closer to his retirement date. Complementary to our analysis in a stationary environment, non-stationary analyse is in fact very difficult since it would require knowing the future evolution of legal rules on retirement date. However, these dates fluctuate with reforms that are difficult to anticipate. We here thus decide to focus on the heterogenity among individuals and not on the heterogeneity over time.

The arrival rate of job offers for an agent $i$, denoted $\lambda_{i}$, depends on the job search effort $\left(e_{i}\right)$ and an efficiency parameter $\alpha_{i} \in[0,1]$, such as :

$$
\lambda_{i}=e_{i}^{\alpha_{i}}
$$

$\lambda^{\prime}(e)>0$ and $\lambda^{\prime \prime}(e)<0$

This efficiency parameter can be defined as :

$$
\alpha_{i}=s_{i} D_{i}
$$

where $s_{i} \in[0,1]$, such that 0 indicates poor health conditions, and $D_{i} \in[0,1]$, such that $D_{i}$ is equal to 0 when the agent retires.

Unlike Ljungqvist and Sargent (2008[35]) or Hairault, Langot, and Sopraseuth (2010[27]) but in line with recent work on search effort in Europe (Kahn, 2009[33]), we assume that the distance to retirement does not affect search effort directly, but rather does so indirectly through the efficiency parameter. That is, older workers might devote the same amount of time to job search as younger unemployed people do, but to be less efficient in this activity. The obsolescence of human capital and lower control over new job search techniques, such as using the Internet and computers (Borghans and TerWeel, 2007[13]) could help explain this lower efficiency. Older workers thus suffer from a technological bias (Aubert, Caroli, Roger, 2006[5]) 
that limits their search efficiency. Moreover, we assume that poor health decreases the search efficiency parameter, by complicating access to job offers and contacts with potential employers. Finally, $\lambda_{i}$ can be written as :

$$
\lambda=e_{i}^{s_{i} D_{i}}
$$

Search costs depends on the job search effort and the efficiency parameter, which in turns reflects health status and distance to retirement. The closer the retirement date and the poorer the person's health, the lower the search efficiency and the greater the search costs are. The search cost, $c\left(e_{i}\right)$, then can be defined as :

$$
c\left(e_{i}\right)=\frac{e_{i}^{2}}{s_{i} D_{i}}
$$

where $c^{\prime}(e)>0$ and $c^{\prime \prime}(e)>0$.

Following Cheron, Hairault and Langot (2007[19], 2011[20]), we assume that the distance to retirement also affects the separation rate, $q$ :

$$
q_{i}=\gamma\left(1-D_{i}\right)
$$

where $\gamma$ is the preference for young employees $(\gamma \in[0,1])$.

Note that when the retirement date is close, $D$ tends toward 0 , and the separation rate depends only on $\gamma$. If firms have a strong preference for young workers, older workers get laid off more. Because European labor legislation protects workers with health problems, firms cannot fire workers because of these problems, so separation rate officially should not depend on $s$.

In each search period, $d t$, an unemployed worker chooses a search intensity, $e_{i}$ and receives unemployment compensation $b$. These benefits can include all pre-retirement schemes that allow older workers to remain in unemployment until they reach the official retirement date (Gruber and Wise, 2005[25]). If the unemployed person finds a job and accepts it, he or she receives a wage, denoted $\omega$, where $f(\omega)$ and $F(\omega)$ are the density and distribution functions, respectively. If the seeker does not find a job, he or she remains unemployed or chooses to retire. With this latter option, the retired worker receives a pension, $p$ that we assume is exogenous.

\subsection{Reservation wage and optimal search effort}

Let $V_{t}$ denote the value of the optimization problem of an unemployed worker and $W_{t}$ the value of the optimization problem of a worker paid $\omega$. The Bellman equations can be written as follows : 


$$
\begin{gathered}
V_{t}=\frac{1}{1+r d t}\left[(b-c(e)) d t+(1-\lambda(e) d t) V_{t}+\lambda(e) d t\left[\int_{0}^{\omega *} V_{t} d F(\omega)+\int_{\omega *}^{\infty} W_{t} d F(\omega)\right]\right] \\
\text { and } W_{t}=\frac{1}{1+r d t}\left[\omega_{t} d t+(1-q d t) W_{t}+q d t V_{t}\right]
\end{gathered}
$$

where $r$ represents the interest rate.

By equalizing $V_{t}$ and $W_{t}$, we obtain the reservation wage $\omega *$ :

$$
\omega *=b-c\left(e_{i}\right)+\frac{\lambda\left(e_{i}\right)}{r+q_{i}} H(\omega)
$$

where :

$$
H(\omega)=\int_{\omega *}^{\infty}(\omega-\omega *) d F(\omega)
$$

The reservation wage equation provides a means to study the trade-off made by an unemployed agent. At each time period, the present value of the expected utility due to employment gets compared against the utility of unemployment, as well as with the expected value of inactivity. Given the possibilities of retiring early, the near-to-retirement worker considers two main options : remain in an active employment situation that depends on the wage proposals receivedor retire. The incomes provided by public insurance and/or employers for an early retirement thus become a key factor. If $\omega *$ is greater than $p$, the worker remains in the labor market. If the wage offer $\omega$ is above $\omega *$, the unemployed person accepts the job; otherwise, he or she remains unemployed. But if $\omega *$ is lower than $p$, the worker retires.

Using the previous equation, we can write :

$$
c\left(e_{i}\right)=b-\omega *+\frac{\lambda\left(e_{i}\right)}{r+q_{i}} H(\omega)
$$

with

$$
c^{\prime}\left(e_{i}\right)=\frac{\lambda^{\prime}\left(e_{i}\right)}{r+q_{i}} \int_{\omega *}^{\infty}(\omega-\omega *) d F(\omega)
$$

Then by combining Equations 8 and 11, we obtain :

$$
\omega *_{i}=b-c\left(e_{i}\right)+\frac{\lambda\left(e_{i}\right)}{\lambda^{\prime}\left(e_{i}\right)} c^{\prime}\left(e_{i}\right)
$$

or, in our case, 


$$
\omega *_{i}=b+e_{i}^{2}\left[\frac{2-s_{i} D_{i}}{\left(s_{i} D_{i}\right)^{2}}\right]
$$

with implies that :

$\frac{\partial \omega *}{\partial D}=\left[\frac{e_{i}^{2}(s D-4)}{s^{2} D^{3}}<0\right]$,

and $\frac{\partial \omega *}{\partial s}=\left[\frac{e_{i}^{2}(s D-4)}{s^{3} D^{2}}<0\right]$.

Our model first predicts that the reservation wage increases with the proximity of the retirement date. Because older workers are less efficient in their job search, they face higher search costs and rationally claim higher reservation wages in contrast with the results offered by Ljungqvist and Sargent (2008[35]) or Hairault, Langot and Sopraseuth (2010[27]). This argument is more consistent with the stylized facts in European countries. Morevover, this distance effect becomes enhanced if older workers have poor health. Optimal search intensity thus depends on distance to retirement and health.

From Equation 11, we have :

$$
\begin{gathered}
\frac{2}{s D} e_{i}=\frac{s D e_{i}^{s_{i} D_{i}-1} H(\omega)}{r+q_{i}} \\
e_{i} *=\left(\frac{2\left(\gamma\left(1-D_{i}\right)+r\right)}{H(\omega) s_{i}^{2} D_{i}^{2}}\right)^{\frac{1}{s_{i} D_{i}-2}}
\end{gathered}
$$

and therefore :

$$
\begin{gathered}
\frac{\partial e *}{\partial s}=-\frac{2^{\frac{1}{s D-2}}\left(\frac{\gamma+r-\gamma D}{H s^{2} D^{2}}\right)^{\frac{1}{s D-2}}\left(s D \log \left(\frac{2(\gamma+r-\gamma D)}{H s^{2} D^{2}}\right)+2 s D-4\right)}{s(s D-2)^{2}}>0 \\
\frac{\partial e *}{\partial D}=-\frac{\left.2^{\frac{1}{s D-2}}\left(\frac{\gamma+r-\gamma D}{H s^{2} D^{2}}\right)^{\frac{1}{s D-2}}\left(s D(\gamma+r-\gamma D) \log \left(\frac{2(\gamma+r-\gamma D)}{H s^{2} D^{2}}\right)-(s D-2)(\gamma D-2 \gamma+2 r)\right)\right)}{D(s D-2)^{2}(\gamma+r-\gamma D)}>0
\end{gathered}
$$

Poor health (a lower value of $s$ ) complicates the job search and increases search costs, so workers with health problems display lower optimal search effort.

Knowing the reservation wage and the optimal effort, we can define the unemployment exit rate, $\theta_{i}$, as the product between the job offers arrival rate and the probability of receiving a wage offer higher than the reservation wage : 


$$
\begin{aligned}
\theta_{i} & =\lambda_{i}[1-F(\omega *)] \\
& =e_{i}^{s_{i} D_{i}}[1-F(\omega *)]
\end{aligned}
$$

We have $\forall i, \frac{d \theta_{i}}{d s_{i}}>0$, and $\frac{d \theta_{i}}{d D_{i}}>0$. Our model thus leads to clear predictions, because older workers and in particlar those who have health problems demand higher reservation wages and display lower effort. Our model also explains why people may prefer to retire. If pensions $p$ are higher than $\omega *$, older workers leave the labor market. As in Ljungqvist and Sargent (2008[35]) or Hairault, Langot and Sopraseuth (2010[27]), generous pensions incite older workers to retire. These theoretical predictions therefore argue for the existence of a distance effect : closer is the retirement date, lower is the employment rate, amplified by a poor state of health. Using French data, we propose then to estimate the probability of being employed according to the distance to retirement and the health status.

\section{Empirical analysis}

\subsection{Data and statistics}

We use the French "Santé et Itinéraires Professionnels" (SIP) survey, conducted in France in 2006 by the health and labour ministries. This survey is original, in that it provides information about both labor market transitions, including retirement, and health status. A representative sample of the French metropolitan population (more than 13,000 people) was interviewed. Each respondent retrospectively declared all known employment events and any illness suffered up until the survey date. These data allowed for the construction of a full calendar of activity (and inactivity) and health events. However, the survey registers only events that last longer than one year, such that it follows that workers who experience a period of unemployment (or inactivity) shorter than one year are considered as employed for that year.

For our analysis, we restrict the sample to male workers in the private sector and who entered the labor market after 1960. This choice is mainly driven by data availability and consistency. Women's professional trajectories are more frequently discontinuous, due to maternity or family commitments, which makes it complicated to estimate an accurate date of retirement. To avoid measurement errors, we focus only on men. Furthermore, in France, the pension calculation rules and retirement date differ in the public sector compared with the private one. We thus include only private sector workers, so that we can investigate workers facing homogenous rules. The final sample includes individuals from the date of entry in the labour market and 
until 2006. Part of them (14.7\%) are older workers (over 55 years) in 2006. Individuals can be unemployed, employed or retired.

Our final sample includes 3,730 men observed for an average of 29 years. By exploiting the panel dimension of the survey, we obtained 90,629 observations.

In addition to individual attributes (see table A1 in the appendix), the SIP survey provides information on the key variables of our theoretical model, namely, employment status, distance to retirement, and health. Note that the SIP survey does not have information on search effort and the reservation wage but only on employment status, which is the outcome of the search behavior, as described in the theoretical part. By following the male workers throughout their careers, we can identify their position in the labor market at each moment in time. On average, 94.59\% of the observations referred employed men, though this high employment rate varies strongly with distance to retirement and health status.

The French pension system is based on a statutory PAYG system. The state pension is calculated on the basis of the person's wage, rate of contribution, and length of period of contribution. The complementary schemes, which complement the general State regime and are compulsory, are also financed on a PAYG basis. To calculate distance to retirement, we use the distance to the age at which full pension can be obtained, which takes into account the legal retirement age, as well as the age at which people are eligible to receive an automatic, full pension, together with the impact of each pension reform on the contributive annuities required to obtain a full pension.

Specifically, to evaluate the distance, we first calculate the full pension age as :

$$
\text { Full pension age } e_{i}=\text { year of first job }+ \text { number of required annuities }- \text { birth year }
$$

If workers are eligible for a full pension before the legal retirement age, they still must wait until this age, which is 60 years for men of our sample. ${ }^{3}$ All members of the workforce obtain the automatic full pension rate at the age of 65 years. Consequently, the distance to retirement $\left(D_{i t}\right)$ is calculated as :

$$
D_{i t}=\min [\max [60, \text { Full pension age }] ; 65]-\text { age }_{i t}
$$

Figure 1 reveals that the employment proportion dramatically decreases with the distance to

\footnotetext{
${ }^{3}$ Since the reform of 2003 , the legal retirement age is 62 years; this reform also introduced the possibility that people with long careers could retire before the age of 60 years, in some conditions.
} 
retirement. These descriptives statistics strongly indicate a distance effect, as we predicted in the theoretical part.

FIGURE 1 : Frequencies of employment according to distance to retirement

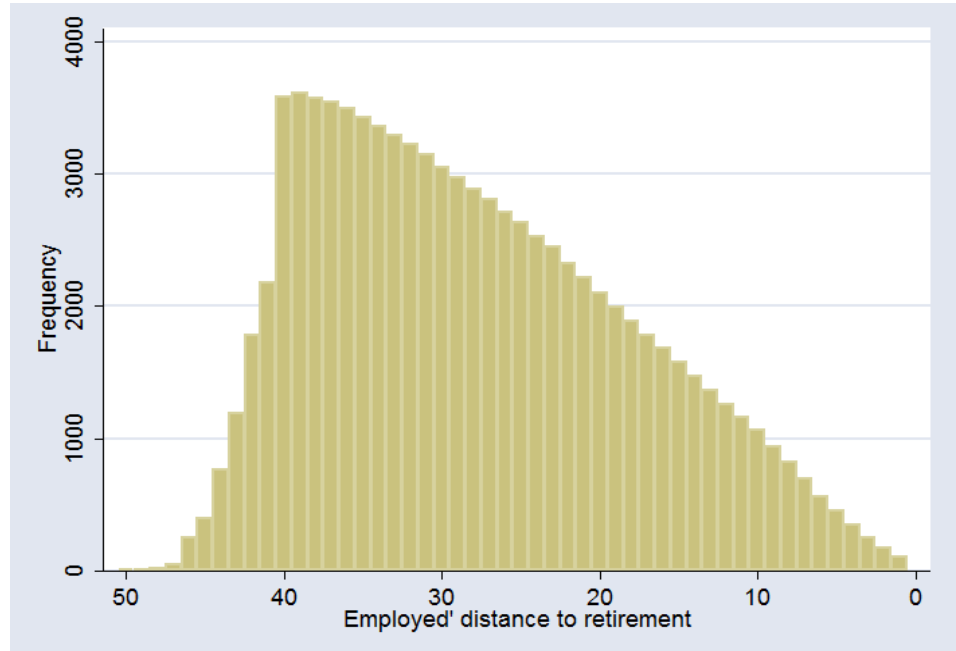

Source : SIP Survey, 2006

Descriptive statistics also show a strong state dependence. Among individuals who are not in employment (in unemployment or in inactivity) at time $t-1,34.75 \%$ were in employment in $t$. This rate raises to $98.78 \%$ when individuals were employed at time $t$-1. This is clearly in line with the literature on employment transitions that highlight that employment status relates closely to status on the labor market in the previous period (Arulampalam, 2002[2]; Fougere and Kamionka (2005[22]).

In addition to distance to retirement and past events in the labour market, health status seems linked with employment. In the SIP survey, health status is defined with an objective indicator, the occurence of at least one illness during the year. This objective measure has two advantages compared with subjective measures, in that it avoids socio-cultural (Bound, 1991[14]) and justification biases. ${ }^{4}$ But objective health and ability to work also tend to correlate strongly. If the activity has a direct impact on health status, it might imply an endogeneity bias (Kerkhofs and Lindeboom, 2002[34]), so we adress this concern in the following estimates.

Because health status differs significantly among individuals, we also consider illness severity. Serious diseases are those that pose a life-threatening or a disability risk, according the CIM Classification. The criterion reveals that $19.98 \%$ of respondents declared they had experienced an illness over the previous year (Table 1), and 3.60\% had a serious disease.

\footnotetext{
${ }^{4}$ The desire to rationalize an early withdrawal from the labor market can prompt near-to-retirement persons to justify their lack of "search activity" by their poor health.
} 
Our descriptive statistics also highlight that the employment rate is lower when illnesses are reported (90.77\% versus $94.59 \%$ for total sample). This employment rate is even lower for men who face a severe desease $(87.67 \%)$. Moreover, health and distance to retirement seem to interact, as in our job search model. Table 1 indicates that the proportion of sick individuals in employment decreases with distance to retirement. Whereas $94.59 \%$ of our observations are employed, only $81.77 \%$ remain in employment when the distance to retirement is less than 5 years. Only $72.15 \%$ of sick individuals remain employed when the distance is less than 5 years, and $61.70 \%$ are employed when they suffer from a serious disease. These statistics clearly signal that worsening health status limits people's ability to work, especially at the end of their careers (Currie and Madrian, 1999 [21]; Au et al., 2005 [4]; Garcia-Gomez, 2011[23]), as we modelled in Section 1.

TABLE 1 : Descriptive statistics : active men

\begin{tabular}{|c|c|c|c|c|}
\hline & Any Distance & $10<D_{i}$ & $5<D_{i} \leq 10$ & $D_{i} \leq 5$ \\
\hline$\%$ in employment & $94.59 \%$ & $94.99 \%$ & $90.87 \%$ & $81.77 \%$ \\
\hline$\%$ of sick observations & $19.98 \%$ & $18.48 \%$ & $41.67 \%$ & $46.60 \%$ \\
\hline$\%$ of seriously sick observations & $3.60 \%$ & $3.35 \%$ & $7.68 \%$ & $6.67 \%$ \\
\hline \multicolumn{5}{|l|}{$\%$ of sick observations } \\
\hline in employment & $90.77 \%$ & $92.32 \%$ & $83.77 \%$ & $72.15 \%$ \\
\hline \multicolumn{5}{|l|}{$\%$ of seriously sick } \\
\hline observations in employment & $87.65 \%$ & $90.50 \%$ & $69.81 \%$ & $61.70 \%$ \\
\hline
\end{tabular}

Our descriptive statistics clearly indicate that distance to retirement and health status can influence the probability of being employed, as defined in our job search model. To specify their respective impacts on employment, we next present results from an econometric analysis.

\subsection{Method}

To analyse the impact of the distance to retirement and health events on the probability of being employed among active men, we use panel probit models, following Hairault et al. (2010[27]). Five configurations are estimated. Focusing on the employment status allows us to capture elder workers' behavior, but also indirectly to take into account labor demand effects : 
an employment relationship is regarded as a match between labor demand and labour supply. The first model is written as :

$$
y_{i t} *=X_{i t} \beta+\epsilon_{i t}, i=1, \ldots, N \text { and } t=1, \ldots, T_{i}
$$

Where :

$$
\begin{gathered}
y_{i t}=1 \text { if } y_{i t} *>0 \text { and } 0 \text { otherwise. } \\
\epsilon_{i t}=\nu_{i t}+u_{i}
\end{gathered}
$$

where $y_{i t}$ is equal to 1 if the individual $i$ is employed at time $t, X$ represents the vector of regressors, $\epsilon_{i t}$ is the composed error term, and $u_{i}$ is the unobserved, individual specific heterogeneity, assumed to be unrelated to $X$. The regressors $X$ include classical employment determinants (educational level, household composition, nationality) and the distance to retirement, calculated for each individual, in each period.

In the second model, we allow for lagged effects, to test for the presence of state dependence. We thus estimate a dynamic random effect model, defined as :

$$
y_{i t} *=X_{i t} \beta+\gamma y_{i, t-1}+u_{i}+\nu_{i t}
$$

The presence of a lagged variable for employment status also raises a question about the initial conditions (Heckman, 1981[28]), because the beginning of a career affects the entire path in the labor market. We then have :

$$
y_{i 0} *=Z_{i 0} \theta+\delta u_{i}+\mu_{i}
$$

though $y_{i 0}$ and the unobserved heterogeneity term also might be correlated. In Equation 21, $E\left(u_{i}\right)=0$, but $E\left[u_{i} \mid y_{i 0}\right] \neq 0$ when $\delta \neq 0$

To address the initial conditions problem, we use Orme's (1997[41]) two-step estimator. This method, according to Arulampalam and Stewart (2009, [3]) is robust as it is not dominated by other popular techniques as those proposed by Heckman's (1981[28]) or Wooldridge (2005[47]) ones. However, note that Miranda(2007, [38]) stressed that the Heckman method may be more robust in the case of high correlation between unobservable terms affecting initial conditions and dynamic equations. This method yet requires a strong hypothesis about the distribution function of unobservable terms. For these reasons, we prefer to use the Orme's method, which is a two steps method. In a first step, we estimate employment status in $t_{0}$ by including $Z_{i 0}$ characteristics (individual attributes and the national employment rate in $t_{0}$ ). Then in a second step, we estimate the following dynamic random effects probit model (assuming a normal distribution for $u_{i}$ ) : 


$$
y_{i t} *=X_{i t} \beta+\gamma y_{i, t-1}+\sigma E\left[u_{i} \mid y_{i 0}\right]+u_{i} *+\nu_{i t}
$$

in which $E\left[u \mid y_{i 0}\right]$ has been estimated in the first step as :

$$
E\left[u \mid y_{i 0}\right]=E\left[u_{i} \mid \delta u_{i}+\mu_{i} \geq-Z_{i t} \theta\right]=\frac{\phi\left(Z_{i t} \theta\right)}{\Phi\left(Z_{i t} \theta\right)}
$$

In model 3, we introduce health status, in line with our theoretical development, both directly and crossed with distance to retirement. Model 4 is thus a reduced form of our job search model.

Model 4 also takes into account the potential endogeneity of health status (Currie and Madrian, 1999[21] ; Kerkhofs and Lindeboom, 2002[34], Madden, 2004[36] ; Brown et al., 2005[16] ; Haan and Myck, 2009[26]). We again adopt a two-step method : first estimating health status, by introducing individual attributes and an instrument that measures the number of illnesses experienced before labor market entry. We also consider the initial conditions problem. ${ }^{5}$ Considering the number of illnesses experienced before labor market entry allows capturing the effects of childhood deseases. A large literature suggests indeed that childhood circumstances have lasting effects on morbidity later in life (Barker 1995[6]; Peck 1994[42]; Preston, Hill and Drevenstedt 1998[43]; Wadsworth 1986[46]). Social and economic deprivation, nutrition, or exposure to environmental toxins and infectious diseases during childhood can influence adult health. Moreover, several empirical analyses support the hypothesis that poor health in childhood is associated with a higher probability of metabolic syndrome in young adulthood (Margolis, 2008[37]).

Finally, the fifth model is a dynamic probit model, with correction of the endogeneity bias caused by the health variable, except that we change the health variable. That is we consider only severe deseases, so that we can test the sensitivity of the distance effect to a more qualitative measure of health.

\subsection{Results}

The main results appear in table 2 ; the intermediate estimates (initial conditions for the employment equation and endogeneity treatment of the illness status) are in the appendix (Tables A2-A6).

\footnotetext{
${ }^{5}$ Health status in $t_{0}$ is instrumented by the medical density, calculated as the ratio between the number of doctors and specialists.
} 
TABLE 2 : Probability of being employed : distance and health

\begin{tabular}{|c|c|c|c|c|c|}
\hline Variables & Model 1 & Model 2 & Model 3 & Model 4 & Model 5 \\
\hline \multirow[t]{2}{*}{ Constant } & 1.317 & 0.222 & 0.621 & -0.172 & -1.241 \\
\hline & $0.061^{* * *}$ & $0.212^{n s}$ & $0.211^{n s}$ & $0.213^{n s}$ & $0.210^{n s}$ \\
\hline \multirow[t]{2}{*}{ Distance to retirement } & 0.012 & 0.023 & 0.012 & 0.009 & 0.025 \\
\hline & $0.002^{* * *}$ & $0.001^{* * *}$ & $0.001^{* * *}$ & $0.002^{* * *}$ & $0.001^{* * *}$ \\
\hline \multirow[t]{2}{*}{ Foreign citizenship } & -0.201 & 0.040 & 0.033 & -0.112 & -0.025 \\
\hline & $0.071^{* * *}$ & $0.065^{n s}$ & $0.063^{n s}$ & $0.064^{n s}$ & $0.065^{n s}$ \\
\hline \multirow{2}{*}{ Having a foreign father } & -0.128 & -0.111 & -0.112 & -0.112 & -0.143 \\
\hline & $0.085^{n s}$ & $0.061^{*}$ & $0.061^{*}$ & $0.061^{*}$ & $0.061^{* *}$ \\
\hline \multirow[t]{2}{*}{ Having a foreign mother } & -0.001 & -0.147 & -0.153 & -0.085 & -0.04 \\
\hline & $0.089^{n s}$ & $0.065^{* *}$ & $0.066^{* *}$ & $0.066^{n s}$ & $0.067^{n s}$ \\
\hline \multirow[t]{2}{*}{ Living in a couple } & 0.959 & 0.143 & 0.134 & 0.443 & 0.475 \\
\hline & $0.023^{* * *}$ & $0.080^{*}$ & $0.079^{*}$ & $0.079^{* * *}$ & $0.029^{* * *}$ \\
\hline \multirow[t]{2}{*}{ Having no diploma } & -0.237 & -0.593 & -0.546 & -0.379 & -0.381 \\
\hline & $0.075^{* * *}$ & $0.062^{* * *}$ & $0.061^{* * *}$ & $0.062^{* * *}$ & $0.066^{* * *}$ \\
\hline \multirow[t]{2}{*}{ Having a high-school diploma } & 0.145 & -0.362 & -0.326 & -0.100 & -0.109 \\
\hline & $0.052^{* * *}$ & $0.062^{* * *}$ & $0.063^{* * *}$ & $0.063^{* * *}$ & $0.041^{* * *}$ \\
\hline \multirow[t]{2}{*}{ Having A-level } & -0.045 & -0.203 & -0.179 & -0.118 & -0.158 \\
\hline & $0.062^{n s}$ & $0.050^{* * *}$ & $0.050^{* * *}$ & $0.049^{* * *}$ & $0.054^{* * *}$ \\
\hline \multirow[t]{2}{*}{ Employment (t-1) } & & 2.404 & 2.362 & 2.358 & 2.398 \\
\hline & & $0.029^{* * *}$ & $0.028^{* * *}$ & $0.028^{* * *}$ & $0.028^{* * *}$ \\
\hline Iinitial conditions in employment & & -1.813 & -1.739 & -1.721 & -1.748 \\
\hline status (Mills ratio) & & $0.415^{* * *}$ & $0.417^{* * *}$ & $0.416^{* * *}$ & $0.417^{2 * * *}$ \\
\hline \multirow[t]{2}{*}{ Having a disease } & & & -0.822 & & \\
\hline & & & $0.063^{* * *}$ & & \\
\hline \multirow[t]{2}{*}{ Disease $^{*}$ Distance } & & & 0.019 & & \\
\hline & & & $0.002^{* * *}$ & & \\
\hline \multirow[t]{2}{*}{ Having a disease (predicted) } & & & & -0.861 & \\
\hline & & & & $0.071^{* * *}$ & \\
\hline \multirow[t]{2}{*}{ Disease $($ predicted $) *$ Distance } & & & & 0.019 & \\
\hline & & & & $0.003^{* * *}$ & \\
\hline \multirow[t]{2}{*}{ Having a severe disease (predicted) } & & & & & -0.819 \\
\hline & & & & & $0.121^{* * *}$ \\
\hline \multirow[t]{2}{*}{ Severe disease (predicted) $*$ Distance } & & & & & 0.018 \\
\hline & & & & & $0.006^{* * *}$ \\
\hline \multirow[t]{2}{*}{ Sigma } & 0.914 & 0.449 & 0.447 & 0.449 & 0.449 \\
\hline & $0.018^{* * *}$ & $0.019^{* * *}$ & $0.018^{* * *}$ & $0.019^{* * *}$ & $0.089^{* * *}$ \\
\hline Loglikelihood & $-14,548$ & $-7,814$ & $-7,716$ & $-7,714$ & $-7,781$ \\
\hline Number of observations & 90,629 & 86,899 & 86,899 & 86,899 & 86,899 \\
\hline
\end{tabular}

These estimates confirm the distance effect, as suggested in life-cycle models (Seater, 1977[45]; Ljungqvist and Sargent, 2008[35]). Using a panel probit model, similar to Hairault, Langot and 
Sopraseuth (2010[27]) or Benallah et al. (2008[9]), we find a significant effect of distance but with smaller intensity (cf. model 1). Being one year closer to the age of retirement decreases the probability of being employed by 1.2 percentage points. The difference in size of marginal effect, compared with previous works, might be attributed to the nature of our data, which follow individual workers throughout their career and not just during a defined period of time (i.e., 46 years in our data versus 7 years at most in other studies). Our distance effect is thus estimated over a longer period. The deadline effect persists even after taking into account persistence effects in the employment equation (model 2). After controlling for prior status in the labor market and for initial conditions (using Orme's method, cf. table A2), we confirm the state dependency in employment probabilities and find that a lower distance to retirement effectively reduces the chances of being employed, by an order of 2.3 percent points each year.

The distance to retirement thus appears to act as a deadline that decreases the probability of being employed. However, this distance effect must be qualified. When we introduce the health condition as an additional explanatory variable, as suggested by our theoretical framework (Section 1), we find two further interesting facts. First, health status has a significant effect on the probability of being employed. From an empirical view, neglecting health status, as previous studies of the distance to retirement and employment have done, actually creates a biased estimate of the distance effect. This bias potentially is quite high, because the marginal effect of health on the probability of being employed is greater than the effect of distance (see model 3). For example, having a disease decreases the probability of being employed by 82 pourcentage points, whereas coming one year closer to the retirement date reduces this same probability by just 1.2 pourcentage points. In addition, our results establish that health status interacts with distance to retirement. For people in poor health, being one year closer to their retirement date decreases the probability of being employed by $3 \%$ - two times the importance we found for a healthy person. This finding confirms one of our theoretical predictions (see Section 1) : poor health reinforces the distance effect.

Second, to test the robustness of the results established in model 3, we address the endogeneity of the health variable (model 4) and introduce a more qualitative measure of health (model 5). We thus can conclude that health status (with or without accounting for the severity of the disease) is well and truly endogenous (See tables A3-A6), as suggested by Madden (2004[36]), Brown et al. (2005[16]), Haan and Myck (2009[26]). It depends on three main factors : prior health status, indivdual attributes, and health environment characteristics (medical density), though prior health status (and initial conditions) offers the greatest explanatory power in relation to current health status. When we correct for this endogeneity of health in the em- 
ployment equation, the conclusions driven from model 3 remain true, because health persists as a key factor explaining the probability of having a job, and its effect largely depends on the distance to retirement. Moreover, the results do not change with illness severity.

\section{Conclusion}

This research has attempted to specify the contribution of the distance effect to the low employment rate of French older workers, by taking health status into account. To that end, we amend McCall's job search model and study the case of heterogenous agents, according to their distance to retirement and their health status. With this theoretical approach, we confirmed the distance effect and also determined that this effect gets reinforced by poor health conditions. Contradicting previous studies (Ljunqvist and Sargent, 2008[35]; Hairault et al., 2010[27]), but consistent with stylized facts, we find that the reservation wage increases with the proximity of the retirement date. Because they are less efficient in their job search, near-toretirement workers face higher search costs, which get amplified even further if they are sick. Consequently, they exhibit lower search effort, leading to reduced job opportunities.

To assess the consistency of our theoretical predictions, we estimated the impacts of the distance to retirement and health status on the probability of being employed, according to individual attributes, using a French data set. We confirm a deadline effect, which remains after we control for persistence effects in the employment equation. Our key results highlight that health, neglected in previous research, actually has a substantial effect on the employment probability. Neglecting health status would lead to important biases, in that its impact is even greater than that of distance. Being ill decreases the probability of employment by a massive 82 pourcentage points, whereas coming one year closer to retirement reduces this probability by only 1.2 pourcentage points. Our conclusions hold even when we address the endogeneity of health in the employment equation, and consider a more qualitative variable of health.

Finally, our findings should not be taken as a challenge to the existence of a distance effect; rather they add nuance to our understanding of its impact. This result has important consequences for economic policy. Specifically, the existence of a distance effect suggests postponing the retirement age, which will encourage people to stay in the labor market longer as predicted by life cycle models. But the benefits of such a policy may be less significant than expected, because they also depend on the health status of the prospective workers. Thus, raising the age of retirement could create inequalities between healthy and sick members of the workforce.

Our study however face two limits. First, in the theoretical framework, it will be useful to go beyond the partial analysis and to develop an equilibrium search model, in order to take into account firms' behaviours. On the empirical side, our dataset does not provide enough complete 
observations about women' careers, and our study is limited to men working in the private sector. Finally, in this article, family interactions are not taken into account. But we know from the literature that not only family commitments but also household organization have an impact on retirement behaviour. For this reason, further research exploring these avenues would be useful to capture more precisely the nature of retirement behaviour. 


\section{References}

[1] J.M. Abowd, F. Kramarz, and D.N. Margolis. High Wage Workers and High Wage Firms. Econometrica, 67(2):251-333, 1999.

[2] W. Arulampalam. State Dependence in Unemployment Incidence: Evidence for British Men Revisited. IZA Discussion paper series, No. 630, November 2002.

[3] W. Arulampalam and M.B. Stewart. Simplified Implementation of the Heckman Estimator of the Dynamic Probit Model and a Comparison with Alternative Estimators. Oxford Bulletin of Economics and Statistics, 71:Oxford Bulletin of Economics and Statistics, 2009 .

[4] D. Au, T.F. Crossley, and M. Schellhorn. The Effects of Health Shocks and Long Term Health on the Work Activity of Older Canadians. Health Economics, 14:999-1018, 2005.

[5] P. Aubert, E. Caroli, and M. Roger. New Technologies, Organisation and Age: Firm-Level Evidence. Economic Journal, 116:73-93, 2006.

[6] D.J.P Barker. Fetal origins of coronary heart disease. British Medical Journal, 311(6998):171-174, 1995.

[7] T. Barnay. Santé declarée et cessation d'activite. Revue Française d'Economie, 20:73-106, 2005.

[8] T. Barnay. Chomage et invalidité apres 50 ans: deux dispositifs alternatifs de sortie de l'emploi pour les seniors en mauvaise santé? Economie et Statistique, 411:47-62, 2008.

[9] S. Benallah, C. Duc, and F. Legendre. Peux t-on expliquer le faible taux d'emploi en france? Revue de l'OFCE, 105:19-54, 2008.

[10] L. Bettendorf and D. Broer. Lifetime Labor Supply in a Search Model of Unemployement. OCFEB Research Memorandum 0308, 2003.

[11] O. Blanchard and J. Wolfers. The Role of Shocks and Institutions in the Rise of European Unemployment : the Aggregate Evidence. Economic Journal, 110:C1-C33, 2000.

[12] D. Blanchet and T. Debrand. Aspiration a la retraite, santé et satisfaction au travail : une comparaison européenne. Questions d'economie de la santé, (103), 2005.

[13] L. Borghans and B. Ter Weel. The Diffusion of Computers and the Distribution of Wages. European Economic Review, 51(3):715-748, 2007.

[14] J. Bound. Self Reported Versus Objective Measures of Health in Retirement Models. Journal of Human Resources, 26:106-138, 1991. 
[15] A. Bozio. Impact Evaluation of the 1993 French Pension Reform on Retirement Age. Pensions: An International Journal, 13:207-212, 2008.

[16] HS. 3rd Brown, JA. Pagan, and E. Bastida. The Impact of Diabetes on Employment: Genetic IVs in Bivariate Probit. Health Economics, 14:537-544, 2005.

[17] K. Burdett and DT. Mortensen. Search, Layoffs and Labor Market Equilibrium. Journal of Political Economy, 88:652-672, 1980.

[18] L. Cai and G. Kalb. Health Status and Labour Force Participation : Evidence from Australia, chapter Health Economics, pages 241-261. Wiley, 2006.

[19] A. Cheron, J.O Hairault, and F. Langot. Job Creation and Job Destruction over the Life Cycle: The Older Workers in the Spotlight. IZA 2597, 2007.

[20] A. Cheron, J.O Hairault, and F. Langot. Age Dependant Employment Protection. Economic Journal, 21:1477-1504, 2011.

[21] M. Currie and B.C. Madrian. Health, Health Insurance and the Labor Market, chapter Handbook of Labor Economics. Amsterdam, North-Holland, 1999.

[22] D. Fougere and T. Kamionka. Econometrics of Individual Labor Market Transitions. IZA DP No. 1850, 2005.

[23] P. Garcia-Gomez. Institutions, Health Shocks and Labour Market Outcomes across Europe. Journal of Health Economics, 30:200-213, 2011.

[24] J. Gruber and D.A. Wise. Social Security Incentives for Retirement around the World. University of Chicago Press, 1999.

[25] J. Gruber and D.A. Wise. Social Security Programs and Retirement around the World: Fiscal Implications. NBER Working Paper 11290, April 2005.

[26] P. Haan and M. Myck. Dynamic of Poor Health and Non-Employment. IZA n4154, April 2009.

[27] JO. Hairault, F. Langot, and T. Sopraseuth. Distance to Retirement and Older Workers' Employment: The Case for Delaying the Retirement Age. Journal of the European Economic Association, 8(5):1034-1076, 2010.

[28] JJ. Heckman. The Incidental Parameters Problem and the Problem of Initial Conditions in Estimating a Discrete Time - Discrete Data Stochastic Process, chapter Structural Analysis of Discrete Data with Econometric Applications. Cambridge: MIT Press, 1981. 
[29] B.T. Hirsch, D.A. Macphersen, and M.A. Hardy. Occupational Age Structure and Access for Older Workers. Industrial and Labor relation Review, 53(3):401-418, 2000.

[30] R. Hutchens. Delayed Payment Contracts and a Firm's Propensity to Hire Older Workers. Journal of Labour Economics, 4:439-457, 1986.

[31] R. Hutchens. Do job opportunities decline with age? Industrial and Labor Relations Review, 42:89-99, 1988.

[32] A.M. Jones, N. Rice, and J. Roberts. Sick of work or too sick to work? Evidence on self-reported health shocks and early retirement from the BHPS. Economic Modelling, $27: 866-880,2010$.

[33] L. Kahn. Temporary Jobs and Job Search Effort in Europe. IZA Discussion Paper 4020, 2009.

[34] M. Kerkhofs and M. Lindeboom. Health and Work of the Elderly Subjective Health Measures, Reporting Errors and the Endogenous Relationship between Health and Work. Journal of Applied Econometrics, 24(6):1024-1046, 2002.

[35] L. Ljunqvist and S. Sargent. Two Questions about European Unemployment. Econometrica, 76(1):1-29, 2008.

[36] D. Madden. Labour Market Discrimination on the Basis of Health : an application to UK Data. Applied Economics, 36(5):421-442, 2004.

[37] R. Margolis. The effects of early childhood diseases on young adult health in guatemala PARC Working Papers WPS 08-07, 2008.

[38] A. Miranda. Dynamic probit model for panel data: A comparison of three methods. United Kingdom Stat Users'Group Meetings 2007, Stata Users Group, 2009.

[39] DT. Mortensen. Job Search and Labor Market Analysis, volume 2 of Handbooks of Labour Economics, chapter 15, pages 849-919. 1986.

[40] S. Nickell. Unemployment and Labor Market rigidities : European versus North America. Journal of Economic Perspectives, 11:55-74, 1997.

[41] C.D. Orme. The Initial Conditions Problem and Two Step Estimations in Discrete Panel Data Models. mimeo, University of Manchester, 1997.

[42] A.M.N. Peck. The importance of childhood socioeconomic group for adult health. Social Science and Medicine, 39:553-562, 1994. 
[43] S.H. Preston, M.E. Hill, and G.L. Drevenstedt. Childhood conditions that predict survival to advances ages for african americans. Social Science and Medicine, 47:1231-46, 1998.

[44] G. Saint-Paul. Does Welfare State Make Older Workers Unemployable? IZA Discussion Papers 4440, 2009.

[45] J. Seater. A Unified Model of Consumption, Labor Supply, and Job Search. Journal of economic theory, 14:349-372, 1977.

[46] M.E. Wadsworth. Serious illness in childhood and its association with laterlife achievement. Class and Health: Research and Longitudinal Data, pages 50-74, 1986.

[47] J. Wooldridge. Simple solutions to the initial conditions problem in dynamic, nonlinear panel data models with unobserved heterogeneity. Journal of Applied Econometrics, 20:39$54,2005$. 


\section{Appendix}

Table A1 Descriptive statistics (2)

\begin{tabular}{cc}
\hline \multicolumn{2}{c}{ Proportion of individuals... } \\
\hline \hline ...having a foreign father & $16.5 \%$ \\
...having a foreign mother & $16.6 \%$ \\
...of foreign citizenship & $14.7 \%$ \\
...living in a couple & $64.6 \%$ \\
...having no diploma & $9.9 \%$ \\
... having a high-school diploma & $59 \%$ \\
...having A-Level & $13.52 \%$ \\
\hline \hline
\end{tabular}

Table A2 - Initial conditions for employment status: probability of being unemployed in t0

\begin{tabular}{lcc}
\hline \multicolumn{1}{c}{ Variable } & Marginal Effect & (Std. Err.) \\
\hline Foreign citizenship & -0.077 & $(0.030)^{* *}$ \\
Having a foreign father & 0.004 & $(0.024)^{n s}$ \\
Having a foreign mother & 0.036 & $(0.027)^{n s}$ \\
Living in a couple & 0.122 & $(0.015)^{* * *}$ \\
Having no diploma & 0.047 & $(0.031)^{*}$ \\
Having a high-school diploma & 0.083 & $(0.018)^{* * *}$ \\
Having A-Level & 0.019 & $(0.021)^{n s}$ \\
Unemployment level in t0 & -0.009 & $(0.002)^{* * *}$ \\
\hline \hline Log likelihood & \multicolumn{3}{c}{-2033.7922} \\
Number of observations & \multicolumn{2}{c}{3,722} \\
\hline
\end{tabular}


Table A3 - Initial conditions for health status: probability of being ill in t0

\begin{tabular}{lcc}
\hline \hline \multicolumn{1}{c}{ Variable } & Marginal effects & (Std. Err.) \\
\hline Age & -0.003 & $(0.004)^{n s}$ \\
Foreign citizenship & -0.024 & $(0.012)^{n s}$ \\
Having a foreign father & 0.020 & $(0.027)^{n s}$ \\
Having a foreign mother & -0.024 & $(0.018)^{n s}$ \\
Living in a couple & -0.009 & $(0.011)^{n s}$ \\
Having no diploma & 0.006 & $(0.022)^{n s}$ \\
Having a high-school diploma & 0.011 & $(0.017)^{n s}$ \\
Having A-Level & -0.010 & $(0.019)^{n s}$ \\
Number of illness during the childhood & 0.028 & $(0.001)^{* * *}$ \\
Medical density in t0 & 0.001 & $(0.000)^{* * *}$ \\
\hline \hline Log likelihood & \multicolumn{2}{c}{3,722} \\
Number of observations & \multicolumn{2}{c}{} \\
\hline
\end{tabular}

Table A4 - Probability of being ill

\begin{tabular}{|c|c|c|}
\hline Variable & Coefficient & (Std. Err.) \\
\hline Being ill in t-1 & 3.961 & $(0.053)^{* * *}$ \\
\hline Age & 0.059 & $(0.008)^{n s}$ \\
\hline Foreign citizenship & 0.237 & $(0.081)^{n s}$ \\
\hline Having a foreign father & -0.129 & $(0.079)^{n s}$ \\
\hline Having a foreign mother & 0.144 & $(0.086)^{n s}$ \\
\hline Living in a couple & 0.062 & $(0.033)^{* * *}$ \\
\hline Having no diploma & 0.288 & $(0.067)^{* * *}$ \\
\hline Having a high-school diploma & 0.321 & $(0.056)^{* * *}$ \\
\hline Having A-Level & 0.255 & $(0.062)^{*}$ \\
\hline Medical density & 0.004 & $(0.002)^{* *}$ \\
\hline Number of illness during the childhood & -0.045 & $(0.024)^{*}$ \\
\hline Initial conditions for health (Mills ratio) & -0.894 & $(0.168)^{n s}$ \\
\hline Constant & -2.047 & $(0.271)^{* * *}$ \\
\hline Sigma & 0.569 & $(0.062)^{* * *}$ \\
\hline Log likelihood & \multicolumn{2}{|c|}{$-6,708,841$} \\
\hline Number of observations & \multicolumn{2}{|c|}{86,899} \\
\hline
\end{tabular}


Table A5 - Initial conditions for health status: probability of having a severe illness in t0

\begin{tabular}{lcc}
\hline \hline \multicolumn{1}{c}{ Variable } & Marginal effects & (Std. Err.) \\
\hline Age & 0.001 & $(0.003)^{* * *}$ \\
Foreign citizenship & -0.006 & $(0.002)^{* * *}$ \\
Having a foreign father & -0.002 & $(0.006)^{n s}$ \\
Having a foreign mother & 0.009 & $(0.005)^{n s}$ \\
Living in a couple & 0.003 & $(0.010)^{n s}$ \\
Having no diploma & 0.010 & $(0.012)^{n s}$ \\
Having a high-school diploma & 0.003 & $(0.004)^{n s}$ \\
Having A-Level & -0.001 & $(0.002)^{n s}$ \\
Number of illness during the childhood & 0.001 & $(0.000)^{* * *}$ \\
Medical density in t0 & 0.001 & $(0.000)^{*}$ \\
\hline \hline Log likelihood & \multicolumn{2}{c}{3,722} \\
Number of observations & \multicolumn{2}{c}{} \\
\hline
\end{tabular}

Table A6 - The probability of having a severe illness

\begin{tabular}{lcc}
\hline \multicolumn{1}{c}{ Variable } & Coefficient & (Std. Err. $)$ \\
\hline Having a severe illness in t-1 & 4.717 & $(0.057)^{* * *}$ \\
Age & 0.029 & $(0.012)^{* * *}$ \\
Foreign citizenship & 0.340 & $(0.236)^{n s}$ \\
Having a foreign father & -0.132 & $(0.095)^{n s}$ \\
Having a foreign mother & -0.018 & $(0.142)^{* *}$ \\
Living in a couple & -0.068 & $(0.057)^{n s}$ \\
Having no diploma & 0.182 & $(0.083)^{* * *}$ \\
Having a high-school diploma & 0.164 & $(0.059)^{* * *}$ \\
Having A-Level & 0.321 & $(0.110)^{* * *}$ \\
Medical density & 0.001 & $(0.002)^{n s}$ \\
Number of illness during the childhood & -0.035 & $(0.025)^{n s}$ \\
Initial conditions for severe deseases (Mills ratio) & -0.420 & $(0.207)^{* *}$ \\
constant & -2.492 & $(0.702)^{* * *}$ \\
\hline Sigma & 0.003 & $(0.018)^{n s}$ \\
\hline \hline Log likelihood & & $-2,026.123$ \\
Number of observations & 86,899 \\
\hline
\end{tabular}

